\title{
Mentorship in anesthesia: a survey of perspectives among Canadian anesthesia residents
}

\section{Le mentorat en anesthésie: un questionnaire sur les perspectives des résidents canadiens en anesthésie}

\author{
Suzan Ergun, MD $($ D $\cdot$ Jason W. Busse, DC, PhD $\cdot$ Anne Wong, MD, PhD
}

Received: 24 May 2016/Revised: 14 November 2016/Accepted: 1 January 2017/Published online: 13 January 2017

(C) Canadian Anesthesiologists' Society 2017

\begin{abstract}
Purpose Mentorship is important for professional and academic growth; however, the role of mentorship in anesthesia is still being defined. We surveyed Canadian anesthesia residents to explore their perceptions of mentorship relationships.

Methods We administered a 20-item cross-sectional survey to program directors and anesthesia residents in all Canadian departments of anesthesia. Program directors were asked about their mentorship programs, and residents were asked about their perceptions of benefits and barriers to effective mentoring.

Results Sixteen of 17 (94\%) program directors and 189 of $585(32 \%)$ anesthesia residents responded to our survey. While 143 of 180 (79\%) residents agreed that mentorship was beneficial to overall success as an anesthesiologist, only 11 of 16 (69\%) program directors reported formal mentorship as part of their residency program, and only 119 of 189 (63\%) residents reported access to a mentor. Barriers reported by residents included insufficient time with mentors, lack of formalized meeting times and objectives, mentor-mentee incompatibility (personal or professional), and lack of resident choice in mentor selection.
\end{abstract}

Conclusion Our study confirms that, despite positive perceptions among residents, mentorship remains underutilized in anesthesia programs. We identify barriers to effective mentorship, including the need to

S. Ergun, MD $(\bowtie) \cdot J$. W. Busse, DC, PhD · A. Wong, MD, PhD

Department of Anesthesia, McMaster University, 1280 Main

Street West, HSC-2V6, Hamilton, ON, Canada

e-mail: suzan.ergun@medportal.ca consider resident choice as a means to improve formal anesthesia mentorship programs.

\section{Résumé}

Objectif Le mentorat est important pour le développement professionnel et académique; toutefois, le rôle du mentorat en anesthésie est encore en cours de définition. Nous avons interrogé des résidents en anesthésie canadiens afin d'explorer leurs perceptions des relations de mentorat.

Méthode Nous avons mené une enquête transversale comprenant 20 éléments auprès des directeurs de programme et des résidents en anesthésie de tous les départements d'anesthésie au Canada. Les directeurs de programme ont répondu à des questions concernant leurs programmes de mentorat, et les résidents à des questions touchant leurs perceptions des avantages et des obstacles à un mentorat efficace.

Résultats Seize des 17 (94\%) directeurs de programme et 189 des 585 (32\%) résidents en anesthésie ont répondu à notre enquête. Alors que 143 résidents sur 180 (79\%) étaient d'accord que le mentorat était bénéfique à une réussite globale en tant qu'anesthésiologiste, seuls 11 des 16 (69\%) directeurs de programme ont noté qu'un mentorat formel était inscrit dans leur programme de résidence, et seuls 119 des 189 (63\%) résidents ont rapporté avoir accès à un mentor. Les obstacles cités par les résidents comprenaient un manque de temps avec leurs mentors, l'absence de temps de rencontre et d'objectifs formels, l'incompatibilité mentor / mentoré (personnelle ou professionnelle), et le manque de choix de mentor pour le résident.

Conclusion Notre étude confirme que, malgré des perceptions positives parmi les résidents, le mentorat demeure sous-utilisé dans les programmes d'anesthésie. 
Nous identifions des obstacles à un mentorat efficace, y compris la nécessité de tenir compte du choix du résident afin d'améliorer les programmes formels de mentorat en anesthésie.

Mentorship is a crucial component of professional development and is associated with increased academic and personal productivity, career advancement, and faculty retention. ${ }^{1-4}$ Additional benefits include the development of superior educational skills, increased confidence, better success with grant applications, and a greater tendency for mentees to pursue an academic career. ${ }^{3-5}$ Benefits for mentors include increased stimulation, personal satisfaction, research productivity, networking, and professional recognition. ${ }^{3,5}$ The Canadian Association of Interns and Residents (renamed Resident Doctors of Canada in 2015) highlighted the importance of academic mentorship by issuing a position paper urging all residency programs to establish formal mentorship programs. ${ }^{6}$

Despite the well-established benefits of academic mentorship, evidence suggests that this training model is often underutilized in anesthesia. A survey of 100 anesthesia trainees in the South Thames region, UK, found that, while $69 \%$ thought they would benefit from mentorship, only $28 \%$ of residents identified a relationship with a mentor. ${ }^{7}$ Another survey of 52 academic anesthesiologists, pre- and postimplementation of a mentorship program, revealed that, while 37 of $52(71 \%)$ respondents thought mentorship was important, only $46 \%$ identified mentorship as part of their academic career development. ${ }^{8}$

In 2013, a survey of Canadian anesthesia residents and program directors $(39 \%$ and $74 \%$ response rates, respectively) found that only $54 \%$ of anesthesia residency programs had formal mentorship programs. ${ }^{9}$ A 2016 qualitative study of anesthesia residents and faculty at the University of Ottawa found that differences in mentormentee expectations were associated with negative mentorship outcomes. ${ }^{10}$ These findings suggest that mentor-mentee relationships continue to be underutilized in anesthesiology and that, even when they exist, barriers for successful mentorship relationships remain.

Our study builds on these important findings by exploring the reasons for the gap between valuing mentorship and enacting these relationships. We examine current formal mentorship programs in Canadian anesthesia residency programs with respect to mentor selection and the benefits and challenges of mentorship from the resident perspective. This information will help guide further optimization of formal mentorship programs for Canadian anesthesia residents.

\section{Methods}

Questionnaire development

With the assistance of an epidemiologist, content experts, and reference to previous literature, ${ }^{3,4}$ we developed a 20 item, English-language questionnaire that examined resident perceptions of mentorship, current mentorship relationships, and perceived benefits and barriers to mentorship (Appendix 1). Response options for attitudinal questions used a seven-point Likert scale $(1=$ strongly agree; $2=$ agree; $3=$ somewhat agree; $4=$ undecided; $5=$ somewhat disagree; $6=$ disagree; $7=$ strongly disagree). We also included an option for respondents to provide written comments regarding any other thoughts they may have concerning mentorship in anesthesia. The final resident surveys were translated into French so that both English- and French-language versions were available for distribution. We pre-tested our final questionnaire with three anesthesia residents to obtain feedback on whether the questionnaire as a whole adequately measured attitudes towards mentorship and if the individual questions reflected the perceptions of benefits and barriers to mentorship relationships. The pretest participants also commented on the clarity and comprehensiveness of the questionnaire. ${ }^{11}$ No changes to the survey were suggested.

We also developed a four-item English-language survey asking anesthesia program directors about their resident demographics, whether their department had a formal mentorship program, how mentors were assigned, and the duration of assigned mentorship relationships (Appendix 2). We pre-tested our questionnaire with three faculty members; only grammatical changes were requested.

The Hamilton Integrated Research Ethics Board approved our study in September 2014. ${ }^{\mathrm{A}}$ In March 2015, we sent e-mail invitations and our four-item survey to program directors of all 17 departments of anesthesia in Canada, identified through the Royal College of Physicians and Surgeons of Canada website (http://www.royalcollege. $\mathrm{ca} /$ portal/page/portal/rc/credentials/accreditation/arps). We solicited their participation in our study and requested that they distribute the resident survey on our behalf. The program directors' survey was sent both by e-mail as an attachment and by hardcopy in the mail. Participating program directors sent their residents an e-mail with a disclosure letter and an online link for our survey, which was hosted by FluidSurveys ${ }^{\circledR}$ (http://fluidsurveys.com/). The survey was accessible for a four-month period from March 1 to June 30, 2015. Copies of our resident survey

\footnotetext{
A We made several revisions to the initial protocol, which resulted in a final approval in February 2015.
} 
were also made available during the McMaster-Western Research Exchange Day and the 2015 Canadian Anesthesiologists' Society annual meeting, with instructions for residents to complete the questionnaire only if they had not previously done so online. In our survey, a mentor was defined as "someone of experience who offers guidance". ${ }^{12,13}$

Data analysis

We generated frequencies for all collected quantitative data. For presentation purposes and to facilitate analysis, we collapsed "agree" and "somewhat agree", and "disagree" and "somewhat disagree" for all survey responses to produce a five-point scale. Missing data were excluded from both the numerator and denominator (complete case analysis). All analyses were performed using IBM SPSS ${ }^{\circ}$ Statistics for Windows (version 22.0, IBM Corp., Armonk, NY, USA).

For our qualitative review of the written comments, two authors (S.E., A.W.) individually read and coded all of the comments in order to identify meaningful data segments. ${ }^{14}$ Related codes were amalgamated under common categories and organized in table form to identify broad common themes. The same authors compared their results to ensure the themes were clearly represented in the data, and they resolved discrepancies through discussion.

\section{Results}

Characteristics of respondents

Our response rate was 16 of $17(94 \%)$ for anesthesia program directors and 189 of $585(32 \%)$ for Canadian anesthesia residents. Eleven of 16 (68\%) programs surveyed reported a formal mentorship program. The majority of program directors surveyed (8 of 11, 73\%) indicated that residents were assigned mentors by their academic program, and only 3 of 11 (27\%) programs allowed residents to select their mentor(s).

One hundred and nine of $189 \quad(58 \%)$ resident respondents were male and 80 of $189(42 \%)$ were female. The majority were ages 26-30, and 172 of 188 $(91.5 \%)$ had completed their undergraduate medical training in Canada. One hundred and nineteen of 188 (63\%) reported access to a mentor (Table 1), and 100 of $112(89 \%)$ of these reported that at least one of their mentors was an anesthesiologist. The number of mentors per resident ranged from 1-10, but most respondents reported access to one (44 of 114, 39\%) or two (38 of 114, $33 \%$ ) mentors. Almost all residents in formal mentorship programs (107 of $116,92 \%)$ reported having been formally
Table 1 Demographics of respondents

\begin{tabular}{ll}
\hline & $n(\%)$ of respondents \\
\hline Sex $(n=189)$ & \\
Male & $109(57.7 \%)$ \\
Female & $80(42.3 \%)$ \\
Age $(n=188)$ & \\
$20-25$ & $12(6.4 \%)$ \\
$26-30$ & $102(54.3 \%)$ \\
$31-35$ & $61(32.4 \%)$ \\
$36-40$ & $9(4.8 \%)$ \\
$>40$ & $4(2.1 \%)$ \\
Level of Resident Training $(n=188)$ & \\
PGY1 & $40(21.3 \%)$ \\
PGY2 & $35(18.6 \%)$ \\
PGY3 & $53(28.2 \%)$ \\
PGY4 & $43(22.9 \%)$ \\
PGY5 & $17(9.0 \%)$ \\
Country of Medical Training $(n=188)$ & \\
Canada & $172(91.5 \%)$ \\
Outside of Canada & $16(8.5 \%)$ \\
Anticipated Practice Environment $(n=188)$ & \\
Academic practice & $66(35.1 \%)$ \\
Community practice & $40(21.3 \%)$ \\
Academic \& community practice & $10(5.3 \%)$ \\
Uncertain & $72(38.3 \%)$ \\
Reports access to a Mentor $(n=188)$ & \\
Yes & $119(63.3 \%)$ \\
No & $69(36.7 \%)$ \\
\hline PGY & \\
\hline & \\
&
\end{tabular}

$\mathrm{PGY}=$ postgraduate year

assigned a mentor, and 74 of $112(66 \%)$ reported access to an "informal" or "non-assigned" mentor.

Perceptions of mentorship

Of those anesthesia residents receiving mentorship, 100 of 117 (86\%) reported benefit; two respondents did not reply to this question. Most respondents indicated that the role of their mentor was to assist them with academic goals (90 of 119, 76\%) or with career opportunities (64 of 119, $54 \%$ ) (Table 2). Residents, in general, agreed that mentorship relationships were beneficial for building confidence (169 of 179, 94\%), development of clinical skills (136 of 178, 76\%), development of teaching skills (147 of 177, 83\%), and achievement of personal goals (140 of 179, 78\%). Residents also thought that mentorship played an important role in promoting faculty retention of trainees within their department (118 of 170, 69\%) (Table 3). Overall, 143 of $180(79 \%)$ residents agreed that mentorship was important to overall success as an anesthesiologist (Table 3). 
Barriers to mentorship

Anesthesia residents reported that barriers to mentorship included a lack of connection between mentor and mentee (131 of $178,74 \%$ ), lack of time among mentors (126 of $180,70 \%$ ), and lack of mentors with similar personal and professional goals (110 of 179, 61\%). Residents also identified lack of formalized meeting times (109 of 177 , $62 \%$ ) or formalized objectives in their mentorship program (103 of $178,58 \%$ ) as barriers. A minority of respondents raised concerns regarding lack of mentors of the same sex

Table 2 Mentorship roles among residents engaged with a mentor $(n=119)$

$n(\%)$ of respondents

Assists with academic goals

$\begin{array}{ll}\text { Yes } & 90(75.6 \%) \\ \text { No } & 29(24.4 \%) \\ \text { Assists with career opportunities } & \\ \text { Yes } & 64(53.8 \%) \\ \text { No } & 55(46.2 \%) \\ \text { Assists with personal/family goals } & \\ \text { Yes } & 43(36.1 \%) \\ \text { No } & 76(63.9 \%) \\ \text { Assists with financial goals } & 11(9.2 \%) \\ \text { Yes } & 108(90.8 \%) \\ \text { No } & \end{array}$

(23 of 175: 8 males and 15 females, 13\%) or absence of mentors with the same cultural background (43 of 179, 24\%) (Table 4).

\section{Written comments}

Thirty-four respondents provided written comments which revealed two major themes: 1) Mentorship is important for professional development (33 comments), as exemplified by the following quote: "I believe mentorship is very beneficial for a trainee in any specialty, it definitely helps to increase confidence and helps the trainee to guide his objective through the residency according to his career plans". 2) The quality of the mentor-mentee relationship is important (18 comments), as exemplified by the following quote: "Formally assigned mentors may be helpful if there was maybe some effort put into matching groups of people with similar interests, goals, or background, i.e., some source of connection, and also if mentors participated voluntarily". An important subtheme was the importance for residents to choose their mentor (12 comments): "Real mentorship happens when established informally as the mentee connects with a mentor who isn't necessarily the assigned mentor".

\section{Discussion}

Anesthesia residents represent the next generation of anesthesiologists and are therefore crucial to the

Table 3 Perspectives regarding the role of mentorship

\begin{tabular}{|c|c|c|c|c|c|}
\hline & $\begin{array}{l}\text { Strongly } \\
\text { Agree } n(\%)\end{array}$ & $\begin{array}{l}\text { Agree } \\
n(\%)\end{array}$ & $\begin{array}{l}\text { Undecided } \\
n(\%)\end{array}$ & $\begin{array}{l}\text { Disagree } \\
n(\%)\end{array}$ & $\begin{array}{l}\text { Strongly } \\
\text { Disagree } n(\%)\end{array}$ \\
\hline Career development $(n=179)$ & $\begin{array}{l}35 \\
(19.6 \%)\end{array}$ & $\begin{array}{l}122 \\
(68.2 \%)\end{array}$ & $\begin{array}{l}15 \\
(8.4 \%)\end{array}$ & $\begin{array}{c}7 \\
(3.9 \%)\end{array}$ & 0 \\
\hline Academic productivity $(n=179)$ & $\begin{array}{l}32 \\
(17.9 \%)\end{array}$ & $\begin{array}{l}116 \\
(64.8 \%)\end{array}$ & $\begin{array}{l}22 \\
(12.3 \%)\end{array}$ & $\begin{array}{l}9 \\
(5.0 \%)\end{array}$ & 0 \\
\hline Grant funding support $(n=160)$ & $\begin{array}{l}16 \\
(10.0 \%)\end{array}$ & $\begin{array}{c}65 \\
(40.6 \%)\end{array}$ & $\begin{array}{l}47 \\
(29.4 \%)\end{array}$ & $\begin{array}{l}25 \\
(15.6 \%)\end{array}$ & $\begin{array}{l}7 \\
(4.4 \%)\end{array}$ \\
\hline Personal goals $(n=179)$ & $\begin{array}{l}23 \\
(12.8 \%)\end{array}$ & $\begin{array}{l}117 \\
(65.4 \%)\end{array}$ & $\begin{array}{l}27 \\
(15.1 \%)\end{array}$ & $\begin{array}{l}11 \\
(6.1 \%)\end{array}$ & $\begin{array}{l}1 \\
(0.6 \%)\end{array}$ \\
\hline Clinical skills $(n=178)$ & $\begin{array}{l}25 \\
(14.0 \%)\end{array}$ & $\begin{array}{l}111 \\
(62.4 \%)\end{array}$ & $\begin{array}{l}23 \\
(12.9 \%)\end{array}$ & $\begin{array}{l}17 \\
(9.6 \%)\end{array}$ & $\begin{array}{l}2 \\
(1.1 \%)\end{array}$ \\
\hline Faculty retention $(n=170)$ & $\begin{array}{l}14 \\
(8.2 \%)\end{array}$ & $\begin{array}{l}104 \\
(61.2 \%)\end{array}$ & $\begin{array}{l}38 \\
(22.4 \%)\end{array}$ & $\begin{array}{l}13 \\
(7.6 \%)\end{array}$ & $\begin{array}{l}1 \\
(0.6 \%)\end{array}$ \\
\hline Teaching skills $(n=177)$ & $\begin{array}{l}23 \\
(13.0 \%)\end{array}$ & $\begin{array}{l}124 \\
(70.1 \%)\end{array}$ & $\begin{array}{l}24 \\
(13.6 \%)\end{array}$ & $\begin{array}{c}6 \\
(3.4 \%)\end{array}$ & 0 \\
\hline Building confidence $(n=179)$ & $\begin{array}{l}63 \\
(35.0 \%)\end{array}$ & $\begin{array}{l}106 \\
(58.9 \%)\end{array}$ & $\begin{array}{c}6 \\
(3.3 \%)\end{array}$ & $\begin{array}{c}4 \\
(2.2 \%)\end{array}$ & $\begin{array}{l}1 \\
(0.6 \%)\end{array}$ \\
\hline $\begin{array}{l}\text { Mentorship is beneficial to overall success } \\
\text { as an anesthesiologist }(n=180)\end{array}$ & $\begin{array}{l}42 \\
(23.3 \%)\end{array}$ & $\begin{array}{l}101 \\
(56.1 \%)\end{array}$ & $\begin{array}{l}20 \\
(11.1 \%)\end{array}$ & $\begin{array}{l}13 \\
(7.2 \%)\end{array}$ & $\begin{array}{l}4 \\
(2.2 \%)\end{array}$ \\
\hline
\end{tabular}


Table 4 Perceived barriers to mentorship

\begin{tabular}{|c|c|c|c|c|c|}
\hline & $\begin{array}{l}\text { Strongly Agree } \\
n(\%)\end{array}$ & $\begin{array}{l}\text { Agree } \\
n(\%)\end{array}$ & $\begin{array}{l}\text { Undecided } \\
n(\%)\end{array}$ & $\begin{array}{l}\text { Disagree } \\
n(\%)\end{array}$ & $\begin{array}{l}\text { Strongly Disagree } \\
n(\%)\end{array}$ \\
\hline Lack of skilled mentors $(n=177)$ & $11(6.2 \%)$ & $77(43.5 \%)$ & $28(15.8 \%)$ & $39(22.0 \%)$ & $22(12.4 \%)$ \\
\hline Lack of time among potential mentors $(n=180)$ & $23(12.8 \%)$ & $103(57.2 \%)$ & $21(11.7 \%)$ & $27(15.0 \%)$ & $6(3.3 \%)$ \\
\hline Lack of financial compensation $(n=174)$ & $11(5.8 \%)$ & $69(39.7 \%)$ & $44(25.3 \%)$ & $33(19.0 \%)$ & $17(9.8 \%)$ \\
\hline Lack of mentors of same sex $(n=175)$ & $2(1.1 \%)$ & $21(12.0 \%)$ & $33(18.9 \%)$ & $78(44.6 \%)$ & $41(23.4 \%)$ \\
\hline Lack of mentors with same cultural background $(n=179)$ & $6(3.4 \%)$ & $37(20.7 \%)$ & $35(19.6 \%)$ & $71(39.7 \%)$ & $30(16.8 \%)$ \\
\hline $\begin{array}{l}\text { Training programs do not have formalized meeting times for } \\
\text { mentorship }(n=177)\end{array}$ & $24(13.6 \%)$ & $85(48.0 \%)$ & $27(15.3 \%)$ & $35(19.8 \%)$ & $6(3.4 \%)$ \\
\hline $\begin{array}{l}\text { Training programs do not have formalized objectives for } \\
\text { mentorship }(n=178)\end{array}$ & $17(9.6 \%)$ & $86(48.3 \%)$ & $32(18.0 \%)$ & $33(18.5 \%)$ & $10(5.6 \%)$ \\
\hline Lack of connection between mentor and mentee $(n=177)$ & $32(18.1 \%)$ & $99(55.9 \%)$ & $23(13.0 \%)$ & $21(11.9 \%)$ & $2(1.1 \%)$ \\
\hline $\begin{array}{l}\text { Lack of mentors with similar personal and professional goals } \\
\qquad(n=179)\end{array}$ & $23(12.8 \%)$ & $87(48.6 \%)$ & $29(16.2 \%)$ & $33(18.4 \%)$ & $7(3.9 \%)$ \\
\hline
\end{tabular}

academic growth of departments. The academic literature is very clear on the benefits of mentorship in terms of increased academic and personal productivity, career advancement, faculty retention of trainees, superior educational skills, increased confidence, increased grant funding, and academic career pursuits. ${ }^{1-5}$ Much of the current academic mentorship literature is derived from other specialties; however, it is important to examine the role of mentorship in anesthesiology specifically due to the profession's unique considerations. First, anesthesiology significantly lags behind other specialties in academic growth and research productivity. ${ }^{15}$ Improved mentorship models may foster better academic growth of the specialty, which is crucial to promoting evidence-based practices. Second, when compared with other specialties, anesthesiologists are at a much higher risk for burnout and other stress-related morbidity. ${ }^{16}$ Mentorship has the potential to improve resilience of the future generation of anesthesiologists. ${ }^{13,17,18}$ Third, anesthesiology as a career specialty may pose special challenges for mentorship. The practice is often solitary and residents are assigned to work with different faculty members on a daily, sometimes $a d$ hoc, basis. This dilutes sustained faculty-resident relationships and may result in insufficient time and opportunities for mentoring.

Interest in mentorship in anesthesiology has recently grown. ${ }^{5,8-10,13,19}$ The 2013 survey of Canadian anesthesia residents found that, despite over $94 \%$ of respondents identifying mentorship during residency training as important, $42 \%$ did not interact regularly with their mentor. ${ }^{9}$ The authors concluded that incorporation of a formal mentorship program within all Canadian anesthesia programs may be helpful. Nevertheless, they did not explore reasons for the gap between valuing mentorship and actual enactment of these relationships.
Our study further builds on these findings by purposely exploring resident perspectives and identifying barriers towards mentorship that may explain this gap. Our study confirms that the majority of Canadian anesthesia residents (79\%) agree that mentorship is important to overall success as an anesthesiologist. Despite this, only 11 of 16 Canadian anesthesia residency programs reported formal mentorship programs. Furthermore, a key finding in our study is that the majority of these formal mentorship programs (73\%) use a predominantly "top-down" dyadic approach where the residents are assigned mentors by their academic program for the full duration of their residency.

A recent qualitative study of 11 anesthesia residents and 12 faculty showed that successful mentorship hinged on three key factors: 1) the anticipated goals of the mentorship relationship, 2) characteristics of participants, and 3) the structure of the program. ${ }^{10}$ The authors concluded that differences in the perception of the goals of the relationship and the structure of the program resulted in cases of disillusionment and negative mentorship outcomes. ${ }^{10}$ Our study revealed similar barriers related to the menteementor relationship and quantified the extent of these issues, including a lack of connection or similar professional or personal goals and a lack of formalized meeting times and objectives in formal programs. The number of written comments provided $(63$ comments from 34 of 189 respondents) was limited; however, the major themes were consistent with our quantitative analysis in affirming the importance of mentorship and, in particular, the quality of the relationship and the need for choice in mentor selection.

There is an obvious disconnect between residents' focus on a quality mentorship relationship that includes choice and the current "top-down" mentorship model in most Canadian anesthesia residency programs. This may explain 
the lack of connection or similar professional or personal goals expressed by the residents. In contrast, research on mentorship in the literature has shown a significant benefit for mentees in informal mentorship relationships (developed spontaneously by choice) compared with formal mentorship (assigned) in terms of satisfaction and professional and psychosocial growth. ${ }^{4,20,21}$

The paradigm shift from a mentor-driven to a menteedriven model has been successfully adopted in business. $^{21,22}$ Furthermore, a number of different mentorship models other than the traditional dyadic model have recently emerged, e.g., the functional, group, and distance mentoring models. ${ }^{21}$ These alternate models can address common barriers to effective mentorship and improve alignment of both mentor and mentee needs. ${ }^{10,21}$

These findings suggest that a top-down approach to mentorship in anesthesiology may not be the most effective. Rather, incorporating more choice and flexibility in mentorship models by granting residents input into the mentor selection process may result in more productive relationships and greater engagement by mentors and mentees.

A limitation of our study is that, while we achieved an excellent response rate $(94 \%)$ for anesthesia program directors, only $32 \%$ of anesthesia residents completed our survey. This response is similar to that reported by Zakus et $a l .{ }^{9}$ but considerably lower than the mean physician response rate of $54 \%$ reported by Asch et al. in their systematic review of postal surveys. ${ }^{23}$ Therefore, selection bias may limit the generalizability of our findings to Canadian anesthesia residents. On the other hand, we can be confident regarding our finding that the majority of anesthesia programs in Canada use a top-down approach to assigning mentors.

Another limitation of our study is that, due to insufficient numbers of residents responding, we were not fully able to explore the role of sex or ethnicity in anesthesia mentorship relationships. This may warrant examination in future studies as the lack of career advancement for females in anesthesiology is well documented. ${ }^{24}$ Females have been found to advance through academic ranks in medicine more slowly than males, and they are less likely to achieve tenured faculty positions in academia. ${ }^{25}$ In general, females in medicine are less likely to have a mentor. ${ }^{3}$ Nevertheless, females with mentors report more publications, more time spent on research activity, and higher career satisfaction than those without mentors. ${ }^{2}$ Likewise, the literature suggests that mentorship based on similar cultural or ethnic backgrounds may result in better acculturation through increased social support. $^{26}$ Thus, the role of sex and ethnicity in mentorship should be further explored in future studies.

While the number of comments available for qualitative analysis was too limited to draw conclusions, the responses did offer additional insight that triangulated with our quantitative findings. Other strengths of our study include developing and conducting our survey in keeping with best practices, ${ }^{11}$ surveying all Canadian anesthesia residents and anesthesia program directors, and providing our resident survey in both of Canada's official languages (French and English).

\section{Conclusions}

Our study confirms the high value that Canadian anesthesia residents place on mentorship and that mentorship programs continue to be underutilized. Barriers to mentorship relate mostly to the quality of the mentormentee relationship, such as a lack of interest, time, or connection-either personal or professional compatibility. Most Canadian anesthesia programs assign mentors to their residents. This approach contrasts with evidence from the literature which suggests that improved satisfaction and professional and psychosocial growth are more likely to occur in mentorship relationships that are not pre-assigned. Our findings suggest that a more meaningful environment for successful mentorship relationships may be facilitated by clear objectives and meeting times, improved matching of residents with mentors (i.e., with similar interests, goals, and motivations), and allowing elements of mentee-driven choice in the selection of mentors.

Acknowledgements We sincerely thank Toni Tidy for administrative assistance and Sun Makosso-Kallyth $\mathrm{PhD}$ for translating our survey into French.

\section{Conflicts of interest None declared.}

Editorial responsibility This submission was handled by Dr. Gregory L. Bryson, Deputy Editor-in-Chief, Canadian Journal of Anesthesia.

Author contributions Suzan Ergun, Anne Wong, and Jason Busse contributed substantially to all aspects of this manuscript, including conception and design; acquisition, analysis, and interpretation of data, and drafting the article.

Funding This study was supported by a Regional Medical Association of Hamilton Scholarship Award through McMaster University. The funding organization had no role in the design and conduct of the study; the collection, analysis, and interpretation of the data; or the preparation, review, and approval of the manuscript.

\section{Appendix 1}

Mentorship in Anesthesia: Surveying the Landscape 
I. Demographics: (circle answer)

Resident level:

a) PGY1 b) PGY 2 c) PGY 3 d) PGY 4 e) PGY 5 f) PGY 5+

Age of Participant:

a) $20-25$ b) $25-30$ c) $30-35$ d) $35-40$ e) $40+$

Gender:

a) Male b) Female c) N/A

Medical Training:

a) International medical graduate b) Canadian medical graduate c) N/A

Career path:

a) Unknown b) Academic practice c) Community practice d) Both

II. Mentorship Relations

1) Do you have a mentor? a) Yes b) No

*Mentor someone of experience who offers you guidance

(If yes please answer Question 1a-1h, if no please proceed to Question 2)

a. Do you think your mentorship relationships are beneficial? (circle answer) Strongly disagree, disagree, somewhat disagree, undecided, somewhat agree, agree, strongly agree, N/A

b. How many mentors do you have?

c. Number of formally assigned mentors (assigned by your academic institution)?

d. Number of informal mentors (organic mentor-mentee relationships)?

e. Number of mentors who are anesthesiologists?

f. Number of mentors with an academic practice?

g. Number of mentors with a career path geared towards community practice?

h. Number of mentors who assist with personal, family, financial goals?

III. Perceptions of Mentorship

Likert scale: $1=$ strongly disagree, 2 = disagree, $3=$ somewhat disagree, $4=$ =undecided, $5=$ somewhat agree, $6=$ agree, $7=$ strongly agree, $\mathrm{N} / \mathrm{A}=$ not applicable

Mentorship in anesthesia is important for:

2) Successful career advancement

$\begin{array}{llllllll}1 & 2 & 3 & 4 & 5 & 6 & 7 & \text { N/A }\end{array}$

3) Increased academic productivity

$\begin{array}{lllllllll}1 & 2 & 3 & 4 & 5 & 6 & 7 & \text { N/A }\end{array}$

4) Increased grant funding

$\begin{array}{lllllllll}1 & 2 & 3 & 4 & 5 & 6 & 7 & \text { N/A }\end{array}$

5) Increased personal productivity

$\begin{array}{llllllll}1 & 2 & 3 & 4 & 5 & 6 & 7 & \text { N/A }\end{array}$

6) Development of clinical skills

$\begin{array}{lllllllll}1 & 2 & 3 & 4 & 5 & 6 & 7 & \text { N/A }\end{array}$

7) Faculty retention

$\begin{array}{lllllllll}1 & 2 & 3 & 4 & 5 & 6 & 7 & \text { N/A }\end{array}$

8) Fostering teaching skills

9) $\begin{array}{llllllll}\text { Building confidence } \\ 1 & 2 & 3 & 4 & 5 & 6 & 7 & \text { N/A }\end{array}$

Likert scale: $1=$ strongly disagree, $2=$ disagree, $3=$ somewhat disagree, $4=$ =undecided, $5=$ somewhat agree, $6=$ agree, $7=$ strongly agree, $N / A=$ not applicable Barriers to mentorship in anesthesia include: 
10) Lack of skilled mentors

$\begin{array}{lllllllll}1 & 2 & 3 & 4 & 5 & 6 & 7 & \text { N/A }\end{array}$

11) Insufficient time available for mentorship

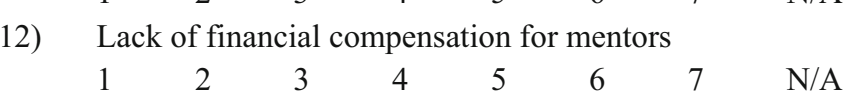

13) Lack of mentors of the same gender

$\begin{array}{llllllll}1 & 2 & 3 & 4 & 5 & 6 & 7 & \text { N/A }\end{array}$

14) Lack of mentors of the same background

$\begin{array}{llllllll}1 & 2 & 3 & 4 & 5 & 6 & 7 & \text { N/A }\end{array}$

15) Mentorship programs that do not have formalized meeting times
$\begin{array}{llllllll}1 & 2 & 3 & 4 & 5 & 6 & 7 & \text { N/A }\end{array}$

16) Mentorship programs that do not have formalized objectives
$\begin{array}{llllllll}1 & 2 & 3 & 4 & 5 & 6 & 7 & \text { N/A }\end{array}$

17) Lack of a personal connection between mentor and mentee
$\begin{array}{llllllll}1 & 2 & 3 & 4 & 5 & 6 & 7 & \text { N/A }\end{array}$

18) Lack of mentors who have similar personal and professional goals

IV Final Section
$\begin{array}{llllllll}1 & 2 & 3 & 4 & 5 & 6 & 7 & \text { N/A }\end{array}$

19) Do you believe you benefit/could benefit from an effective mentorship relationship in terms of overall success as an anesthesiologist? (circle answer) Strongly disagree, disagree, somewhat disagree, undecided, somewhat agree, agree, strongly agree, N/A

20) Comments about mentorship in anesthesiology:

If you would like to be entered into a draw to win a gift certificate for your time and effort, please provide your email: Please note that your email will not be linked to your responses on the survey.

\section{Appendix 2}

\section{Survey for Program Directors:}

1. Name of Institution

2. Total Number of Residents in your department

\# males \#females

3. Do you have a formal mentorship program for residents with faculty?
[] Yes
[] No (please proceed to question \#4)

a. How are the resident mentorship relationships arranged (check all that apply)

[] Pre-assignment [] Self-selection [] Other (please specify)

b. Is there a set duration of the formal relationships (if so how long)?

4. Do you have a formal mentorship program for faculty?

[] Yes (proceed with following sub-questions) [] No

a. How are the faculty mentorship relationships arranged?

[] Pre-assignment [] Self-selection [] Other (please specify)

b. Is there a set duration of the formal relationships (if so how long)? 


\section{References}

1. Feldman MD, Arean PA, Marshall SJ, Lovett M, O'Sullivan P. Does mentoring matter: results from a survey of faculty mentees at a large health sciences university. Med Educ Online 2010; 23: 15 .

2. Levinson W, Kaufman K, Clark B, Tolle SW. Mentors and role models for women in academic medicine. West J Med 1991; 154: 423-6.

3. Sambunjak D, Straus SE, Marusic A. Mentoring in academic medicine: a systematic review. JAMA 2006; 296: 1103-15.

4. Sambunjak D, Straus SE, Marusic A. A systematic review of qualitative research on the meaning and characteristics of mentoring in academic medicine. J Gen Intern Med 2010; 25: 72-8.

5. Flexman AM, Gelb $A W$. Mentorship in anesthesia. Curr Opin Anaesthesiol 2011; 24: 676-81.

6. Jaswal J, Noy S, Yarascavitch A. CAIR position paper on mentorship. 2013. Available from URL: http://residentdoctors.ca/ publications/position-papers/ (accessed November 2016).

7. Gould G. Mentor system for anaesthesia trainees. Anaesthesia 2004; 59: 411.

8. Farag E, Abd-Elsayed AA, Mascha EJ, O'Hara JF Jr. Assessment of an anesthesiology academic department mentorship program. Ochsner J 2012; 12: 373-8.

9. Zakus $P$, Gelb AW, Flexman AM. A survey of mentorship among Canadian anesthesiology residents. Can J Anesth 2015; 62: 9728.

10. Alisic $S$, Boet $S$, Sutherland $S$, Bould $M D$. A qualitative study exploring mentorship in anesthesiology: perspectives from both sides of the relationship. Can J Anesth 2016; 63: 851-61.

11. Burns KE, Duffett $M$, Kho ME, et al. A guide for the design and conduct of self-administered surveys of clinicians. CMAJ 2008; 179: 245-52.

12. Berk RA, Berg J, Mortimer $R$, Walton-Moss B, Yeo TP. Measuring the effectiveness of faculty mentoring relationships. Acad Med 2005; 80: 66-71.
13. Flexman $A M$, Gelb $A W$. Mentorship in anesthesia: how little we know. Can J Anesth 2012; 59: 241-5.

14. Braun V, Clarke V. Using thematic analysis in psychology. Qual Res Psychol 2006; 3: 77-101.

15. Schwinn DA, Balser JR. Anesthesiology physician scientists in academic medicine: a wake-up call. Anesthesiology 2006; 104: 170-8.

16. Thomas I, Carter JA. Occupational hazards of anaesthesia. Contin Educ Anaesth Crit Care Pain 2006; 6: 182-7.

17. Wagner IJ, Hultman CS. Elevation: developing a mentorship model to raise the next generation of plastic surgery professionals. Ann Plast Surg 2013; 70: 606-12.

18. DeCastro R, Sambuco D, Ubel PA, Stewart A, Jagsi R. Batting 300 is good: perspectives of faculty researchers and their mentors on rejection, resilience, and persistence in academic medical careers. Acad Med 2013; 88: 497-504.

19. Miller DR, McCartney CJ. Mentoring during anesthesia residency training: challenges and opportunities. Can J Anesth 2015; 62: 950-5.

20. Ragins BR, Cotton JL. Mentor functions and outcomes: a comparison of men and women in formal and informal mentoring relationships. J Appl Psychol 1999; 84: 529-50.

21. Kashiwagi DT, Varkey P, Cook DA. Mentoring programs for physicians in academic medicine: a systematic review. Acad Med 2013; 88: 1029-37.

22. Zerzan JT, Hess R, Schur E, Phillips RS, Rigotti N. Making the most of mentors: a guide for mentees. Acad Med 2009; 84: 140-4.

23. Asch DA, Jedrziewski MK, Christakis NA. Response rates to mail surveys published in medical journals. J Clin Epidemiol 1997; 50: 1129-36.

24. Wong CA, Stock MC. The status of women in academic anesthesiology: a progress report. Anesth Analg 2008; 107: 178-84.

25. Nonnemaker $L$. Women physicians in academic medicine: new insights from cohort studies. N Engl J Med 2000; 342: 399-405.

26. Atri A, Matorin A, Ruiz P. Integration of international medical graduates in U.S. Psychiatry: the role of acculturation and social support. Acad Psychiatry 2011; 35: 21-6. 